\title{
Valorization of Swine Manure into Hydrochars
}

\author{
Zac Lentz, Praveen Kolar* and John J. Classen * \\ Biological and Agricultural Engineering, Campus Box 7625, North Carolina State University, \\ Raleigh, NC 27695-7625, USA \\ * Correspondence: pkolar@ncsu.edu (P.K.); classen@ncsu.edu (J.J.C.); Tel.: +1-919-513-9797 (P.K.); \\ +1-919-515-6755 (J.J.C.)
}

Received: 22 June 2019; Accepted: 14 August 2019; Published: 23 August 2019

check for updates

\begin{abstract}
There is a significant interest in valorizing swine manure that is produced in enormous quantities. Therefore, considering the high moisture content in swine manure, the objective of this research was to convert manure slurry into hydrochars via hydrothermal carbonization and analyze the yields, $\mathrm{pH}$, energy contents, and thermal and oxidation kinetic parameters. Experiments were performed in triplicate in $250 \mathrm{~mL}$ kettle reactors lined with polypropylene at $180{ }^{\circ} \mathrm{C}, 200{ }^{\circ} \mathrm{C}, 240{ }^{\circ} \mathrm{C}$, $220^{\circ} \mathrm{C}$, and $260^{\circ} \mathrm{C}$ for $24 \mathrm{~h}$. Analyses of the results indicated that the process temperature affected the hydrochar yields, with yield generally decreasing with increasing temperature, but it had little effect on the composition of the hydrochar. The hydrochars were found to have higher volatile contents and $\mathrm{H} / \mathrm{C}$ and $\mathrm{O} / \mathrm{C}$ ratios and about $85 \%$ of the energy compared to coal. However, the presence of high fraction (35-38\%) of ash in hydrochars is a serious concern and needs to be addressed before the complete utilization of hydrochars as fuels. The surface characterization of hydrochars coupled with wet chemistry experiments indicated that hydrochars were equipped with nitrogen functional groups with points of zero charges between 6.76 and 7.85, making them suitable as adsorbents and soil remediation agents and energy storage devices.
\end{abstract}

Keywords: swine manure; valorization; char; hydrothermal carbonization; characterization

\section{Introduction}

Swine farming forms a major part of the agricultural portfolio in many countries. For example, in the United States alone, swine farmers produced about 66 million pigs (with a value of approximately $\$ 22.5$ billion), which in turn produced about 73 million tons of manure each year [1,2]. If not handled properly, the components of manure, namely, organic carbon, nitrogen, phosphorus, potassium, heavy metals (e.g., copper, zinc, cadmium), hormones, and steroids, can negatively impact the environment [3]. Currently available technologies for manure management and treatment include anaerobic lagoons, anaerobic digestion for methane production, and composting $[4,5]$.

Anaerobic lagoons involve treatment of manure in earthen ponds where the components of the manure, i.e., urea, proteins, and organic solids, are transformed into ammonia, hydrogen sulfide, methane, carbon dioxide, and nitrogen by a symbiotic interaction of aerobic and anaerobic microbes [6-9]. As a result, nitrogenous, carbonaceous, and sulfurous compounds are lost to the atmosphere (although phosphorus is retained as a component of the digestate (end product), commonly known as sludge), resulting in environmental, health, and social problems and legal problems in the areas where these concentrated animal farming operations are located, such as North Carolina. Hence, it was proposed to digest manure anaerobically to produce methane [10]. However, being a biochemical process, anaerobic digester systems have slower methane production rates and require large footprints [11]. Similarly, composting could produce valuable fertilizer although they suffer from problems similar to anaerobic digestion. Therefore, alternative technologies have to be tested that can process the massive 
quantities of manure that are produced annually in the US and other parts of the world where animal agriculture is concentrated.

One promising technology to process swine manure is hydrothermal carbonization (HTC) [12]. The HTC process involves the thermal treatment of carbon-containing organic components along with water at moderate temperature conditions ranging from 100 to $260{ }^{\circ} \mathrm{C}$ and at autogenous pressures greater than $0.1 \mathrm{MPa}[13,14]$. During HTC, in addition to the elimination of pathogens, hormones, steroids, antibiotics, and other endocrine disruptors, the organic components undergo hydrolysis, dehydration, decarboxylation, and polymerization, during which oxygen and hydrogen contents are decreased, and carbon and energy content of the organic material is increased $[15,16]$. The end product of the HTC process is called hydrochar, which possesses rather unique properties depending on the mode of processing [17]. For example, hydrochars could be utilized as an energy source via combustion [18]. Hydrochars derived from various biomass have been found to be comparable to bituminous and lignite coals based on chemical composition $[19,20]$ Considering the United States and other countries' interest in clean coal technologies and the already available infrastructure, hydrochars could be utilized effectively to decrease fossil fuel demand in the US, as long as they can be produced and converted to energy at least as inexpensively as coal [21]. Similarly, hydrochars can also be used as adsorbents for mitigation of environmental pollutants from water, especially when the surfaces are functionalized with certain (e.g., oxygen and nitrogen) functional groups [22]. Recently, carbon materials functionalized with nitrogen, sulfur, and phosphorous are being actively explored as carbon electrodes for supercapacitors [23]. Therefore, swine manure-derived hydrochars, due to the presence of N, S, and P in manure, are excellent candidates for supercapacitor applications. Finally, as suggested by $[24,25]$, hydrochars find applications as soil remediation as well.

From a process standpoint, swine manure is an excellent candidate for HTC due to the presence of high moisture [26]. As a result, researchers have been focusing on the HTC of swine manure not only to produce hydrochars but also to recover valuable nutrients from manure. The authors of Cao et al. [27] used dried and dewatered swine manure solids to produce hydrochars at $250{ }^{\circ} \mathrm{C}$ and observed an increased density of aromatic groups when compared to raw manure perhaps due to polymerization of intermediate compounds that were formed during carbohydrate decomposition. In their research, Helimann et al. [28] tested HTC processes to convert swine and other manures into hydrochars, thereby immobilizing phosphorous within the hydrochar matrices. Further, the hydrochars that were synthesized during the HTC process were found to be a carbon-neutral energy source similar to sub-bituminous coals [28]. Similarly, the authors of [29] evaluated the HTC of swine manure for nutrient extraction by varying $\mathrm{pH}$ to determine the impact of the presence of acids and bases on the recovery of nitrogen and phosphorus from manure. In research by Gasco et al. [30] synthesized and compared hydrochars (via HTC) and biochars (via pyrolysis) from swine manure and reported that hydrochars were equipped with more developed porosities than biochar and therefore very suitable as a soil media. Additionally, Liu et al. [31] suggested that swine manure-derived hydrochars serve as a better soil amendment matrix than rice straw-derived hydrochars. The authors, Song et al. [11] investigated the HTC of swine manure and reported that the physicochemical properties of hydrochars produced in the process conformed to NY525 2012 standards. The same group also reported that HTC was a quick route to synthesize hydrochars equipped with fertilizer qualities [4]. However, the authors observed that the HTC process tends to concentrate phosphorus and heavy metals such as copper and zinc in the hydrochars, especially when the process temperatures and times were increased. Similarly, the accumulation of phosphorus and potassium in swine manure-derived hydrochars was also reported by [30]. Recently, a mixture of swine manure and corn stalk was converted into hydrochar via HTC by Lang et al. [5]. Their analyses suggest that the ignition temperatures of hydrochars prepared from swine manure were greater than those of hydrochars prepared from corn stalks. In a different study [3], the same authors reported that the addition of $\mathrm{CaO}$ enhanced the yield and the alkalinity of the hydrochars, opening up enormous possibilities of treating acidic soils via application of hydrochars. 
Despite the recent efforts to evaluate the HTC of swine manure, detailed information regarding the chemical properties of the hydrochars and their subsequent utilization for energy is still not completely available. Hence, the objective of this study was to investigate the HTC of swine manure to determine the fractional yields, elemental and chemical compositions (specifically, carbon, oxygen, and nitrogen), energy contents, and thermal and kinetic characteristics of hydrochars across a range of operating temperatures.

\section{Materials and Methods}

\subsection{Materials}

Swine manure was collected from the settling basin at NC State University's Lake Wheeler Road Field Labs in Raleigh, NC. The manure was collected in two buckets and then homogenized using a cordless drill and paint mixer before storing manure in one-liter bottles. Manure from three of the bottles was used, and samples from each were dried at $105^{\circ} \mathrm{C}$ for $24 \mathrm{~h}$. Dried manure samples were submitted to NC State University's Environmental and Agricultural Testing Service (EATS) for analysis using a Perkin Elmer 2400 CHNS Analyzer to determine elemental C, N, H, and S by total combustion, with oxygen being determined by difference. Proximate analysis of dried manure was completed using a TA Instruments Q500 Thermogravimetric Analyzer (TGA).

\subsection{Hydrothermal Carbonization Experiments}

HTC experiments were conducted using three $250 \mathrm{~mL}$ polypropylene (PPL)-lined kettle reactors loaded with $100 \mathrm{~mL}$ of homogenized manure. The polypropylene liners were weighed before and after being loaded with manure to measure starting manure mass. The reactors were heated between $180^{\circ} \mathrm{C}$ and $260{ }^{\circ} \mathrm{C}$ for $24 \mathrm{~h}$ in a Fisher Scientific Isotem oven, and the resulting hydrochars were subsequently labeled HC-180, HC-200, HC-220, HC-240, and HC-260, respectively. Most of the reports in the literature on the HTC of manures focused on short (1-3 h) and medium (up to $10 \mathrm{~h}$ ) processing times. Considering that actual swine manure is usually collected as a slurry and is heterogeneous, longer reaction times may be needed for complete carbonization. Therefore, in this research, we tested a longer process time of $24 \mathrm{~h}$ to investigate the quality of hydrochars and compare with those obtained from shorter [31] and medium processing times obtained by $[4,11]$.

The selected range of temperatures was based on other HTC experiments [27-29]. The use of several levels across the temperature range was intended to determine if decreases in char yield due to carbon densification decrease linearly with temperature, or if simultaneous reactions cause the temperature to have a more complex impact on char yields. All carbonization experiments were performed in triplicate for $24 \mathrm{~h}$ without stirring. After allowing the reactors to cool, the PPL liners and manure products were weighed. The liquid product was poured off and measured, and then each PPL liner with solid products was weighed. The liners were then placed in a Thermo Electron Corp Linberg/Blue M oven set at $105^{\circ} \mathrm{C}$ for $24 \mathrm{~h}$ and allowed to cool in a desiccator, and then weighed before and after dried solids were removed to determine the mass of dry hydrochar produced. A total of 18 separate experiments were performed to synthesize hydrochars which were analyzed for physical and chemical properties.

\subsection{Analysis of Hydrochars}

Proximate and ultimate analyses were performed on the dried solids and hydrochar to determine the influence of temperature on char chemical composition and to allow for comparison of the chars to fossil fuel coals. Samples were pulverized and sieved through a No. 60 mesh $(0.250 \mathrm{~mm})$. For elemental analysis, hydrochar samples were submitted to NC State University's Environmental and Agricultural Testing Service (EATS) for analysis using a Perkin Elmer 2400 CHNS Analyzer to determine elemental $\mathrm{C}, \mathrm{N}, \mathrm{H}$, and $\mathrm{S}$ by total combustion. 
Proximate analysis was completed at the NC State Chemical Analysis and Spectroscopy Laboratory (CASL) using TA Instruments Q 500 Thermogravimetric Analyzer (TGA). Samples were held at $110^{\circ} \mathrm{C}$ and then $900^{\circ} \mathrm{C}$ in the presence of nitrogen to determine moisture and volatile contents, then switched to air at $900{ }^{\circ} \mathrm{C}$ to determine fixed carbon and ash contents. Despite proximate analysis standards prescribing that samples be heated up to $950{ }^{\circ} \mathrm{C}, 900^{\circ} \mathrm{C}$ was the maximum temperature used due to equipment limitations but is not expected to have significantly impacted results, as Elder (1983) shows practically no further weight loss occurs beyond $900^{\circ} \mathrm{C}$ and is common practice with proximate analysis performed via TGA [32-34]. The raw TGA data were analyzed via TA Universal Analysis software.

Dynamic bomb calorimetry was performed using a C5000 Calorimetric System (IKA, Wilmington, NC, USA). The surface of the samples was also analyzed via X-ray photoelectron spectroscopy (XPS) to understand the speciation of nitrogen on the surface of the hydrochars. The data were deconvoluted using CasaXPS (Version 2.3.18). The peak assignments and parameters for carbon, oxygen, and nitrogen were chosen based on comparable char analyses as described by $[35,36]$.

The data were analyzed via SAS 9.4. Comparisons of char yields and characteristics were made using Tukey's studentized range test with $\alpha=0.05$. The effects of temperature on product yields and characteristics were tested using Type III analysis of variance (ANOVA) $(\alpha=0.05)$; the null hypothesis of these tests was that there is no difference between the chars, or that temperature has no significant impact on char formation.

\section{Results and Discussion}

\subsection{Hydrochar Yield}

The chemical composition of the raw manure is presented in Table 1. Because this study was focused on utilizing fresh manure slurry directly as a feedstock as opposed to dried manure solids and water, as other studies have used, the mass of solids in the heterogeneous feedstock for each experiment was not easily controllable $[27,29]$. Hence, hydrochar yields based on mass did not allow for a meaningful comparison, so hydrochar yields were reported as a percentage of manure solids in the feedstock. Hydrochar yields for each temperature can be seen in Figure 1.

Maximum yield occurred at the lowest temperature tested, $180{ }^{\circ} \mathrm{C}$, and decreased linearly to $220^{\circ} \mathrm{C}$ with very little change beyond $220^{\circ} \mathrm{C}$. The minimum yield was at $240{ }^{\circ} \mathrm{C}$, though this was not significantly different from the slightly higher average yields at $220^{\circ} \mathrm{C}$ and $260^{\circ} \mathrm{C}$ according to Tukey's studentized range test ( $p=1.0000$ and 0.0531 , respectively). The temperature had a significant influence on hydrochar yield $(p<0.0001)$. Reactor effect was also tested to determine if the particular reactor used added to the variability of mass yield and was determined not to have a significant effect $(p=0.9712)$. Given that the char production at $220^{\circ} \mathrm{C}, 240{ }^{\circ} \mathrm{C}$, and $260^{\circ} \mathrm{C}$ was not statistically different, the relationship is more likely to be a linear decrease in the range of 180-220, where it levels off until some temperature at which gasification would become more prevalent. This is consistent with the literature, which indicates that decarboxylation and dehydration occur from 180 to $200{ }^{\circ} \mathrm{C}$, resulting in the steep decrease in product mass over this range [15]. Further fluctuations in char yields can be attributed to polymerization and condensation reactions which are more prevalent beyond $200{ }^{\circ} \mathrm{C}$ when the reactive compounds freed by decarboxylation and dehydration interact with char surface. The effect of temperature on hydrochar yield was similar to [31], who investigated the HTC of pig manure $\left(180-300^{\circ} \mathrm{C}\right)$ for $1.5 \mathrm{~h}$. However, the overall yield of hydrochar obtained in our research was somewhat higher than those (56.7-43.7\%) presented by [17] in a similar temperature range. Our results also agree with those of [30], where yields between $48\left(240^{\circ} \mathrm{C}\right)$ and $58 \%\left(200^{\circ} \mathrm{C}\right)$ were observed, and with those of [11], despite lower reaction times of $2 \mathrm{~h}$ and $1 \mathrm{~h}$, respectively, although our yields at lower temperature ranges were higher than the yields reported by $[11,30]$. In a separate report, the authors of [4] systematically tested three residence times of 1,5 , and $8 \mathrm{~h}$ for temperatures $160-240{ }^{\circ} \mathrm{C}$ and observed that while the yields generally decreased with an increase in temperatures for each time 
regime tested, the yields beyond $5 \mathrm{~h}$ were similar, suggesting that reaction times beyond $5 \mathrm{~h}$ may not be necessary for optimum conversion of manure into hydrochar.

Table 1. Chemical composition (wt \%) of the feedstock (swine manure) on a dry, ash-free basis.

\begin{tabular}{cccc}
\hline Manure Bottle & A & B & C \\
\hline Solids & 8.4 & 7.1 & 8 \\
Moisture & 8.6 & 6.9 & 7.1 \\
Volatile Matter & 58.9 & 60.2 & 59.1 \\
Fixed Carbon & 7.2 & 7.7 & 7.4 \\
Ash & 25.3 & 25.2 & 26.4 \\
Carbon & 54.3 & 58.4 & 58.2 \\
Hydrogen & 7.5 & 7.9 & 7.8 \\
Nitrogen & 5.1 & 5.1 & 4.3 \\
Sulfur & 1.7 & 1.9 & 1.9 \\
Oxygen & 31.5 & 26.8 & 27.9 \\
\hline
\end{tabular}

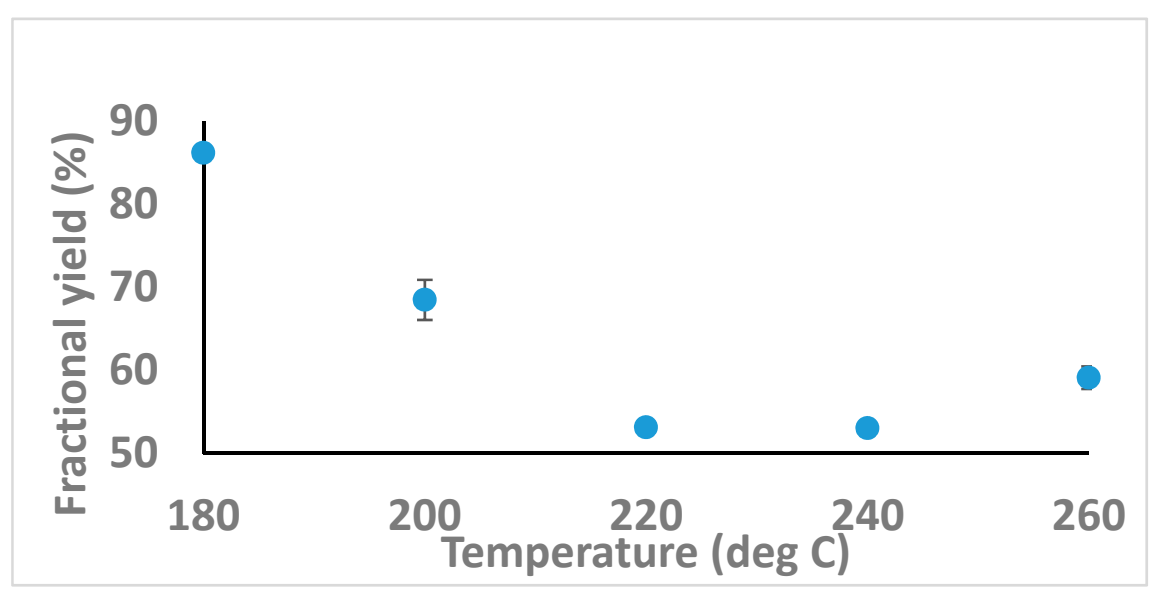

Figure 1. Effect of temperature on the yield of hydrochar from manure (fractional yield vs. temperature).

\subsection{Characterization of Hydrochar}

While it is evident that the yield of solids varied with temperature, the composition of the chars based on proximate and ultimate analyses (Table 2) showed that char composition did not vary significantly with temperature.

Table 2. Proximate and ultimate analysis of hydrochar.

\begin{tabular}{cccccc}
\hline Char & HC-180 & HC-200 & HC-220 & HC-240 & HC-260 \\
\hline \multicolumn{5}{c}{ Proximate (wt \%): } \\
\hline Moisture & $2.8 \pm 0.9$ & $2.6 \pm 0.3$ & $1.7 \pm 0.2$ & $2.4 \pm 0.1$ & $4.6 \pm 1.3$ \\
Volatile Matter & $48.1 \pm 3.7$ & $48.0 \pm 0.9$ & $44.6 \pm 1.2$ & $48.0 \pm 0.7$ & $45.1 \pm 1.8$ \\
Fixed Carbon & $11.0 \pm 0.6$ & $11.9 \pm 0.3$ & $15.4 \pm 0.3$ & $14.5 \pm 0.6$ & $14.7 \pm 0.2$ \\
Ash & $38.0 \pm 3.3$ & $37.5 \pm 0.6$ & $38.2 \pm 1.0$ & $35.1 \pm 0.9$ & $35.6 \pm 3.1$ \\
\hline \multicolumn{7}{c}{ Ultimate (wt \%, d.b. ash-free): } \\
\hline Carbon & $63.2 \pm 6.9$ & $73.1 \pm 6.2$ & $70.0 \pm 9.8$ & $71.9 \pm 1.4$ & $70.2 \pm 5.8$ \\
Hydrogen & $7.6 \pm 0.8$ & $8.6 \pm 1.0$ & $7.7 \pm 1.4$ & $8.0 \pm 0.1$ & $7.6 \pm 0.6$ \\
Nitrogen & $4.9 \pm 0.2$ & $4.8 \pm 0.2$ & $4.3 \pm 0.3$ & $4.4 \pm 0.1$ & $5.2 \pm 0.2$ \\
Sulfur & $0.9 \pm 0.2$ & $1.0 \pm 0.1$ & $0.9 \pm 0$ & $1.0 \pm 0$ & $0.8 \pm 0.1$ \\
Oxygen & $23.4 \pm 7.9$ & $12.5 \pm 7.3$ & $17.1 \pm 11.4$ & $14.7 \pm 1.6$ & $16.3 \pm 6.6$ \\
\hline
\end{tabular}


Notably, some uncertainty remains regarding the oxygen content of the chars since it was determined by difference $(100 \%-\% \mathrm{C}-\% \mathrm{H}-\% \mathrm{~N}-\% \mathrm{~S}-\%$ ash). Therefore, reported values for oxygen content may have been impacted by an accumulated error which likely led to the large standard deviations for oxygen content in several of the chars. Overall, the average chemical formula for the chars produced was determined to be $\mathrm{CH}_{1.35} \mathrm{O}_{0.18} \mathrm{~N}_{0.06}$.

The temperature did not have a significant influence on the elemental composition for hydrochar $(p<0.0001)$, however. For each char, the relative quantity of each element was $\mathrm{C}>\mathrm{O}>\mathrm{H}>\mathrm{N}>\mathrm{S}$. Despite these results, the carbon and oxygen contents of HC-180 were noticeably different from the rest; carbon content was lower, and oxygen content was higher. HC-180 was the only sample with carbon content less than the average and was one of two samples with oxygen content higher than the average, though it was $6.6 \%$ higher compared to HC-220, which was only $0.3 \%$ higher. This was expected since HTC is known to cause carbon densification with increased temperature, but Tukey's studentized range test results indicated that the difference was not significant $(p=0.7178)$. However, the fixed carbon content was significantly impacted by temperature and increased with temperature $(p<0.00001)$, despite the maximum being at the middle temperature, $220^{\circ} \mathrm{C}$. Increasing fixed carbon content is to be expected with increasing temperature, as decarboxylation and dehydration cause carbon to densify. Moisture, volatile matter, and ash contents were not significantly impacted by temperature. From a nutrient accumulation perspective, the hydrochars produced in our research were similar to those of Song et al. [11] who reported that the sulfur, nitrogen, phosphorus, potassium, and ash contents were $0.6-1 \%, 4.2-4.7 \%, 1.5-2.6 \%, 1-2 \%$, and $17-21 \%$, respectively. Similar results were reported by Lang et al. [3] who synthesized hydrochars that contained $2-3 \%$ nitrogen, $0.38-0.48 \%$ sulfur, along with $21-36 \%$ ash. Further, it was observed that the recovery of nitrogen from the manure into hydrochar was about $40 \%$ [37].

Beyond how these hydrochars compare to each other, it is important to determine how they compare to the feedstock and fossil fuel coals. This comparison can be made using the van Krevelen diagram (Figure 2), a common means of comparison for coals, which charts atomic ratios of hydrogen and oxygen to carbon as described by [30]. The highest rank coals are plotted in the bottom left corner of the diagram and have the lowest $\mathrm{H} / \mathrm{C}$ and $\mathrm{O} / \mathrm{C}$ ratios. Carbonization enhances biomass for consumption as a solid fuel by removing hydrogen and oxygen, causing densification of carbon. Before HTC, dried manure had oxygen and hydrogen content higher than low-rank brown coal. After HTC, hydrochar oxygen and hydrogen contents were reduced. Swine manure hydrochar had an O/C ratio between low bituminous coal and brown coal, but a higher $\mathrm{H} / \mathrm{C}$ ratio than coal. A similar trend was also reported by [31] for the HTC of swine manure, where increased temperatures from 180 to $30{ }^{\circ} \mathrm{C}$ decreased the $\mathrm{H} / \mathrm{C}$ ratios from 1.18 to 0.91 . Similarly, based on the data presented by [11], the $\mathrm{H} / \mathrm{C}$ ratios were found to decrease from 1.75 to 1.42 when the temperature was increased from 140 to $220{ }^{\circ} \mathrm{C}$. Recently, the authors of [3] observed that while $\mathrm{H} / \mathrm{C}$ ratios generally decreased (1.75 to 1.29) with an increase in temperature, the addition of $\mathrm{CaO}$ appeared to increase the $\mathrm{H} / \mathrm{C}$ ratio due to carbon decomposition, although increased $\mathrm{CaO}$ concentration decreased the $\mathrm{H} / \mathrm{C}$ ratio. These results suggest that HTC results in the densification of carbon while simultaneously decreasing the oxygen and hydrogen from the hydrochar. 


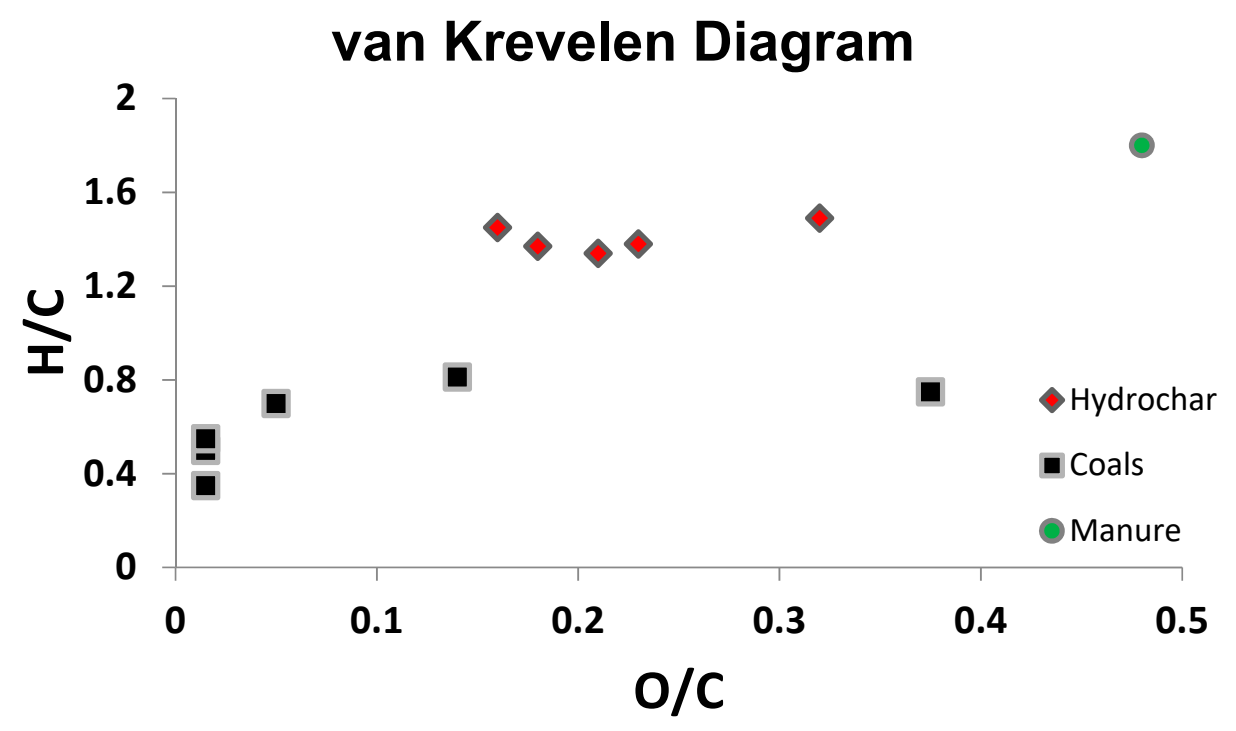

Figure 2. The van Krevelen plots for manure-derived hydrochars and coals (H/C vs. O/C).

Additionally, from a practical perspective, the presence of heteroatoms (noncarbon atoms) in hydrochars may play a significant role, especially when hydrochars are applied as soil amendments. Typically, swine manure contains heavy metals such as copper, zinc, iron, and inorganic minerals such as phosphorus, calcium, and magnesium [38,39]. These are added as a part of feed formulation to enhance the growth of the animals and feed conversion ratio in confined operations [40]. During the HTC process, the heavy metals and minerals present in biomasses have been reported to accumulate within the carbon matrix [41]. For example, in their research, Song et al. [11] observed that despite an initial dip, the concentrations of copper and zinc increased by $74 \%$ and $86 \%$ when temperatures were increased from $140{ }^{\circ} \mathrm{C}$ to $220^{\circ} \mathrm{C}$. In a study by the same group [4], copper, zinc, and phosphorus accumulated significantly in hydrochars synthesized from swine manure when processed at temperatures between 160 and $240{ }^{\circ} \mathrm{C}$ (1-8 $\mathrm{h}$ residence time). Despite their accumulation in hydrochars, the actual environmental impact of these heavy metals may depend on the exact form of the immobilized metals in the carbon matrix. For example, Lang et al. [37] investigated the HTC of swine manure and swine manure-biomass mixtures. Their analyses indicated that the HTC of swine manure at $220^{\circ} \mathrm{C}$ for $10 \mathrm{~h}$ increased the concentration of zinc, copper, manganese, and chromium by about $81 \%, 79 \%, 82 \%$, and $56 \%$, respectively. Interestingly, when the authors performed systematic speciation of metals, it was found that HTC generally reduced the biologically available and toxic proportion of these heavy metals. Recently, Jin et al. [12] also transformed digestates of swine and dairy manure into hydrochars (at $220^{\circ} \mathrm{C}$ for $4 \mathrm{~h}$ ) and reported that the heavy metals accumulated in hydrochars were a relatively stable form.

\subsection{XPS Analysis}

X-ray photoelectron spectroscopy (XPS) was employed to elucidate differences in surface chemical species between dried manure and two hydrochars, HC-180 and HC-240. The survey spectra (Figure 3) revealed the presence of carbon, oxygen, and nitrogen for each sample. Additionally, the low-temperature char (HC-180) and dried manure surveys revealed traces of calcium, and the dried manure had a minor surface phosphorus peak, which suggested the presence of orthophosphate. 


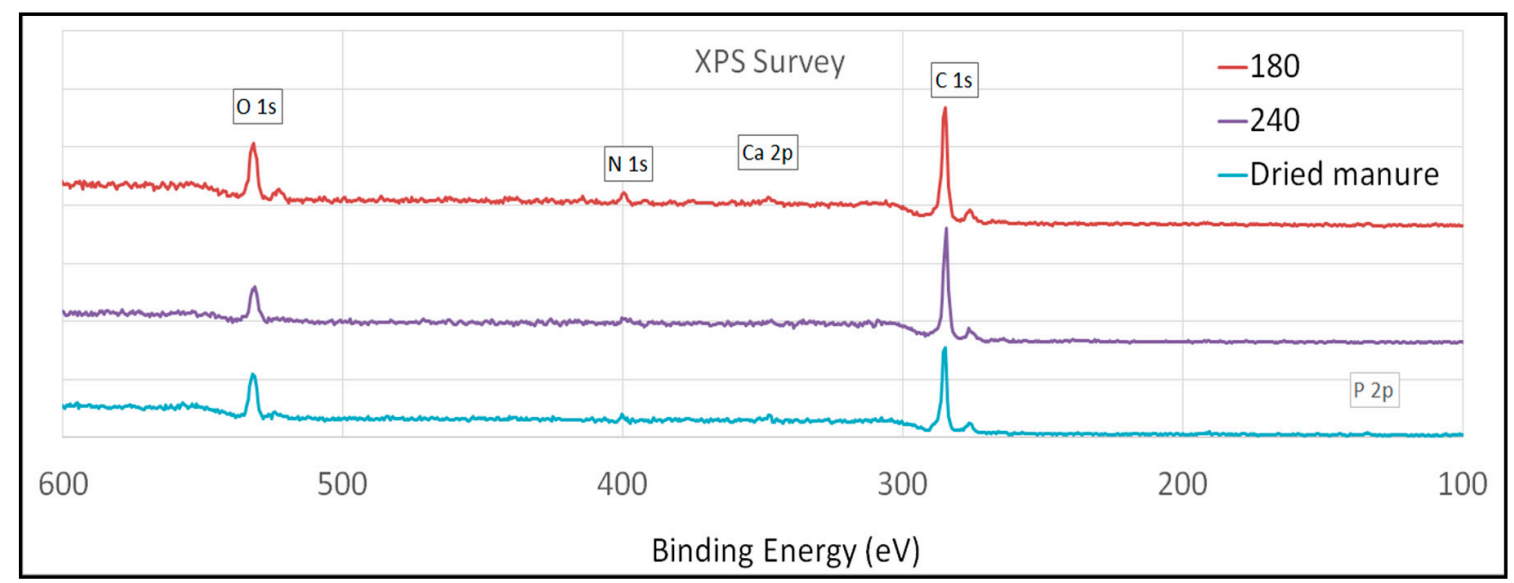

Figure 3. Representative X-ray photoelectron spectroscopy (XPS) plots of hydrochars and dried manure $\left(\times 10^{3}\right.$ CPS vs. Binding Energy).

The surface elemental composition (Table 3) suggested that carbonization of manure led to increased carbon and decreased oxygen contents on the char surfaces. These trends that were more pronounced as char preparation temperature increased from 180 to $240{ }^{\circ} \mathrm{C}$.

Table 3. The atomic composition of char and manure surfaces.

\begin{tabular}{ccccccccc}
\hline & C 1s & C * & N 1s & O 1s & Ca 2p & P 2p & O/C & O/C * \\
\hline Manure & $76.1 \%$ & $69.9 \%$ & $2.9 \%$ & $18.6 \%$ & $1.2 \%$ & $1.3 \%$ & 0.24 & 0.35 \\
HC-180 & $77.7 \%$ & $75.1 \%$ & $4.1 \%$ & $17.1 \%$ & $1.1 \%$ & $0 \%$ & 0.22 & 0.27 \\
HC-240 & $85.5 \%$ & $83.4 \%$ & $1.7 \%$ & $12.8 \%$ & $0 \%$ & $0 \%$ & 0.15 & 0.14 \\
\hline \multicolumn{8}{c}{ * From the ultimate analysis, adjusted to exclude hydrogen. }
\end{tabular}

Deconvoluted spectra for carbon, oxygen, and nitrogen can be seen in Figure 4 (and Supplementary Figure S1) and revealed a surface predominantly covered by the ring structures, accounting for $60-75 \%$ of the atoms on the surface. Many of the remaining surface compounds were aliphatic hydrocarbons bonded to the ether, hydroxyl, and carbonyl groups. The carbon peak was dominated by cyclopentane and larger rings, which became more pronounced with increasing temperature. Overall, aromatic carbon accounted for greater than $70 \%$ of the carbon for each sample.

As expected, the oxygen content in the manure decreased from $18.6 \%$ to $17.1 \%$ when treated at $180{ }^{\circ} \mathrm{C}$, and $12.8 \%$ when treated at $240{ }^{\circ} \mathrm{C}$. Very little of the oxygen $(<4 \%$ of oxygen) was found to be contained in aromatic groups. The prominence of the particular oxygen peaks varied slightly with increasing carbonization, suggesting that oxygen removal occurs uniformly without higher volatilization for any particular oxygen-containing species. Overall nitrogen content increased with carbonization at $180{ }^{\circ} \mathrm{C}$ but decreased with higher temperature. While pyrrolic nitrogen $(400.3 \mathrm{eV})$ decreased with temperature as pyridinic nitrogen (398.7) increased, quaternary nitrogen (401.4 eV) followed the same trend as overall nitrogen content.

With increasing carbonization temperature (manure $<180{ }^{\circ} \mathrm{C}<240{ }^{\circ} \mathrm{C}$ ), the portion of carbon detected that can be attributed to aromatic carbon content increased as overall carbon content increased, confirming that carbonization occurred as oxygen-containing functional groups volatilized. While deconvoluted carbon spectra for manure and HC-180 were quite similar, HC-240 showed higher cyclopentane peaks (33\% of carbon compared to $10 \%$ ) and lower peaks for large rings ( $9 \%$ of carbon compared to $\sim 22 \%$ ). Alternatively, with nitrogen, the smaller pyrrolic rings decreased from $76 \%$ to $68 \%$ to $54 \%$, while the larger pyridinic rings increased from $12 \%$ to $28 \%$ to $31 \%$. Interestingly, the presence of heterocyclic pyridinic and pyrrolic nitrogen groups within the carbon matrix has significant implications, especially when the hydrochars are used as soil amendments and adsorbents. The pyridinic nitrogen equipped with a lone pair of electrons can serve as a Lewis base and can 
potentially serve as an active site for removal of adsorption of compounds with electrophilic centers. Similarly, the presence of pyrrolic nitrogen with a carbon structure has been shown to selectively adsorb chromium [42]. In addition, there is a significant interest in nitrogen-rich carbons as precursors to supercapacitors [43]. Hydrochars equipped with pyridinic, pyrrolic, and quaternary nitrogen groups are naturally well suited for supercapacitor applications.

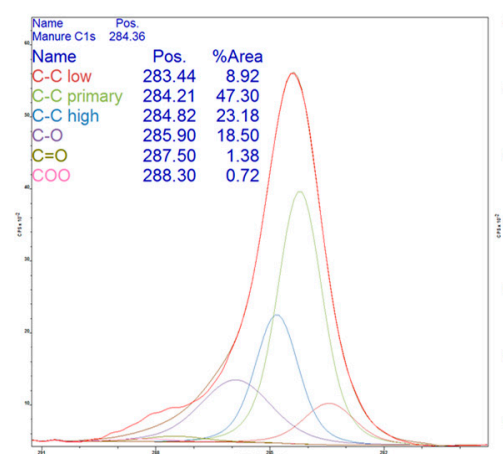

4(a) Manure C $1 \mathrm{~s}$

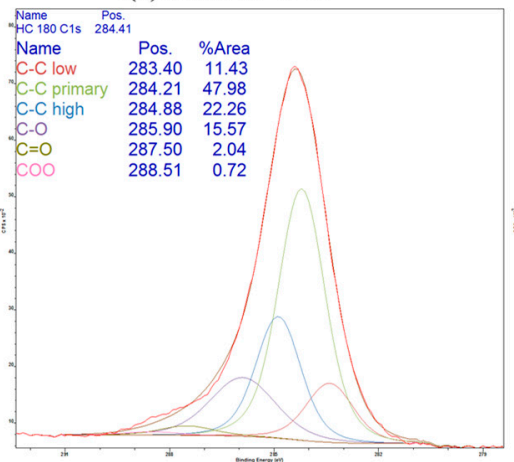

4(d) HC-180 C ls

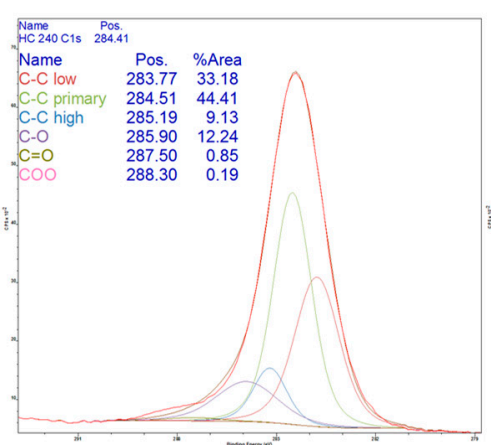

$4(\mathrm{~g}) \mathrm{HC}-240 \mathrm{C} 1 \mathrm{~s}$

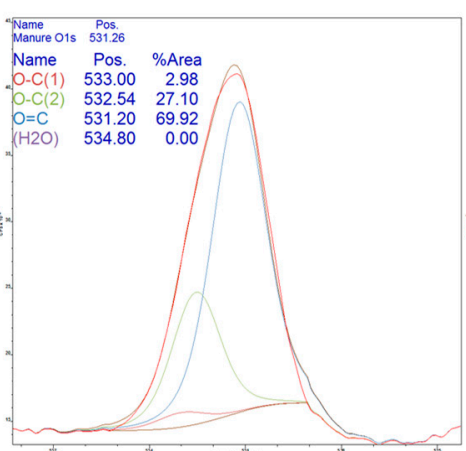

4(b) Manure O 1s

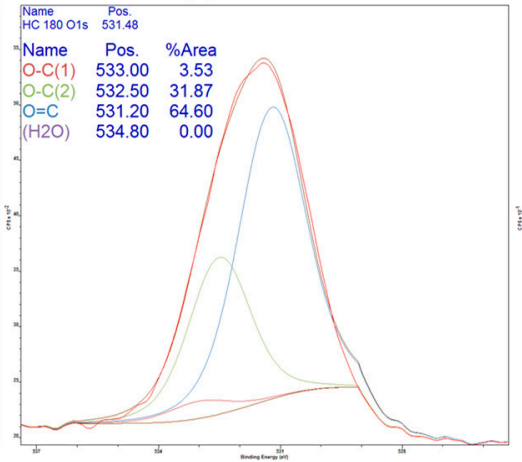

4(e) HC-180 O 1s

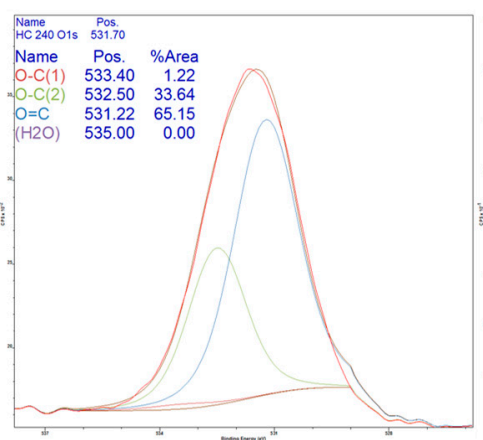

4(h) HC-240 O $1 \mathrm{~s}$

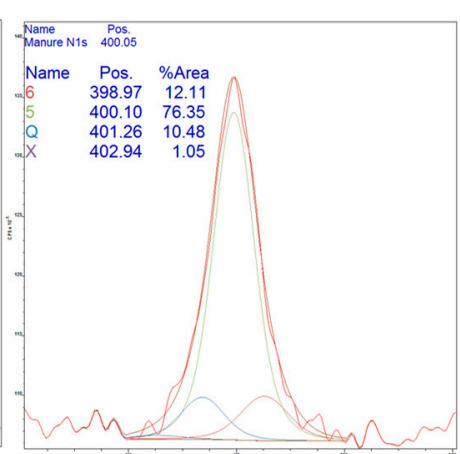

4(c) Manure N $1 \mathrm{~s}$

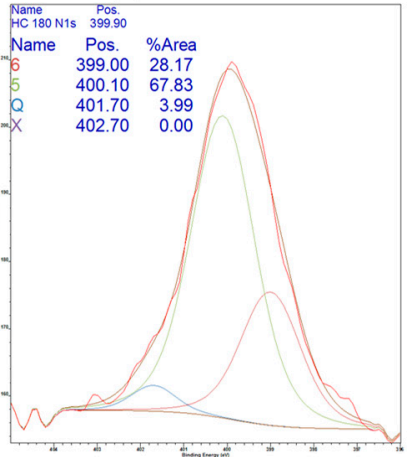

4(f) HC- $180 \mathrm{~N} 1 \mathrm{~s}$

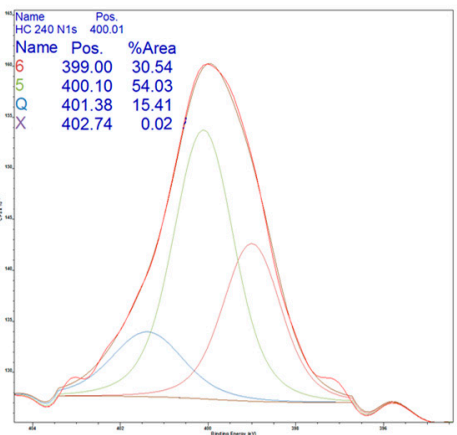

4(i) $\mathrm{HC}-240 \mathrm{~N} 1 \mathrm{~s}$

Figure 4. Deconvoluted $\mathrm{C}, \mathrm{O}$, and $\mathrm{N}$ peaks from XPS analysis of manure and hydrochars $(\mathrm{C}-\mathrm{C}$ low: cyclopentanes, $\mathrm{C}-\mathrm{C}$ primary: cyclohexanes, $\mathrm{C}-\mathrm{C}$ high: cycloheptanes, 5: pyridinic, 6: pyrrolic, Q: quaternary nitrogen, and $\mathrm{X}$ : pyridine-N-oxide).

The trends toward carbon densification, as evidenced by decreasing oxygen and oxygen-bound carbon, suggested that hydrothermal carbonization of swine manure occurs via the same mechanisms suggested for carbonization of other feedstocks. Since dehydration and decarboxylation are known to be the prominent mechanisms across this temperature range, it can be inferred that these are causing the initial structures to decompose as they release water and carboxyl groups [28]. The decrease in cycloheptanes and large cycloalkanes and overall oxygen content present in HC-240 compared to manure and HC-180 suggest that large rings were decomposed as oxygen compounds volatilized. 
The increase in cyclopentane may be attributed to aromatization of surface structures remaining after water and carboxyl groups were liberated from the char surface.

\section{4. $p H$ Analyses of Hydrochars}

As shown in Table 4, the $\mathrm{pH}$ of the hydrochars appeared to generally increase with the reaction temperature. Our results were similar to those of [11], where a gradual increase was also observed in $\mathrm{pH}$ from 5.8 to 6.5 when temperatures were increased from $140{ }^{\circ} \mathrm{C}$ to $220^{\circ} \mathrm{C}$. However, in our study, the measured $\mathrm{pH}$ values were slightly higher, perhaps due to longer reaction times that resulted in the synthesis of nitrogen groups on the surface, which may have increased the $\mathrm{pH}$ value of the hydrochar. In addition, the points of zero charge (PZC) were also found to increase from 6.76 to 7.85 and decrease when the temperature was increased beyond $220^{\circ} \mathrm{C}$. The PZC values are important especially when hydrochars are applied as soil amendments or as adsorbents. When the $\mathrm{pH}$ of the system is higher than PZC, the hydrochars will be negatively charged and can interact with positively charged substrates. Similarly, when the $\mathrm{pH}$ of the system is lower than PZC, hydrochars acquire a positive charge can interact with negatively charged species [44].

Table 4. Effect of temperatures on surface $\mathrm{pH}$ and points of zero charge (PZC) of hydrochars.

\begin{tabular}{cccccc}
\hline Temperature $\left({ }^{\circ} \mathbf{C}\right)$ & $\mathbf{1 8 0}$ & $\mathbf{2 0 0}$ & $\mathbf{2 2 0}$ & $\mathbf{2 4 0}$ & $\mathbf{2 6 0}$ \\
\hline pH & 6.25 & 6.38 & 6.85 & 6.65 & 6.88 \\
PZC & 6.76 & 6.87 & 7.85 & 7.45 & 7.42 \\
\hline
\end{tabular}

\subsection{Energy Density}

The energy density of the chars, as determined by bomb calorimetry, ranged from 17.7 to $20.8 \mathrm{MJ} / \mathrm{kg}$, with an average of $19.6 \mathrm{MJ} / \mathrm{kg}$. Our results were similar to those of [45], where microwave-assisted HTC of coconut shell was investigated. However, in our research, no clear trend existed based on temperature, which was determined not to have a statistically significant influence on energy density $(p=0.2670)$. On average, the energy densities of these chars were $14 \%$ lower than the content of the coal consumed in the US, $22.7 \mathrm{MJ} / \mathrm{kg}$ [46]. The lower energy density was likely due to the higher $\mathrm{H} / \mathrm{C}$ and $\mathrm{O} / \mathrm{C}$ ratio and ash content (37\%) of the chars compared to more carbon-dense coal. When compared to dried manure $(16 \mathrm{MJ} / \mathrm{Kg})$, HTC resulted in a $23 \%$ increase in energy density. Further, when the energy densities were transformed into energy yields as described by [41], the results indicated that the energy yields were between $95.3 \%$ and $76.8 \%\left(180-260^{\circ} \mathrm{C}\right)$.

\subsection{Thermogravimetric Analysis}

Thermogravimetric (TG) analysis and differential thermogravimetric (DTG) data (Figure 5a,b) were analyzed to determine the thermal and kinetic properties of the chars. 

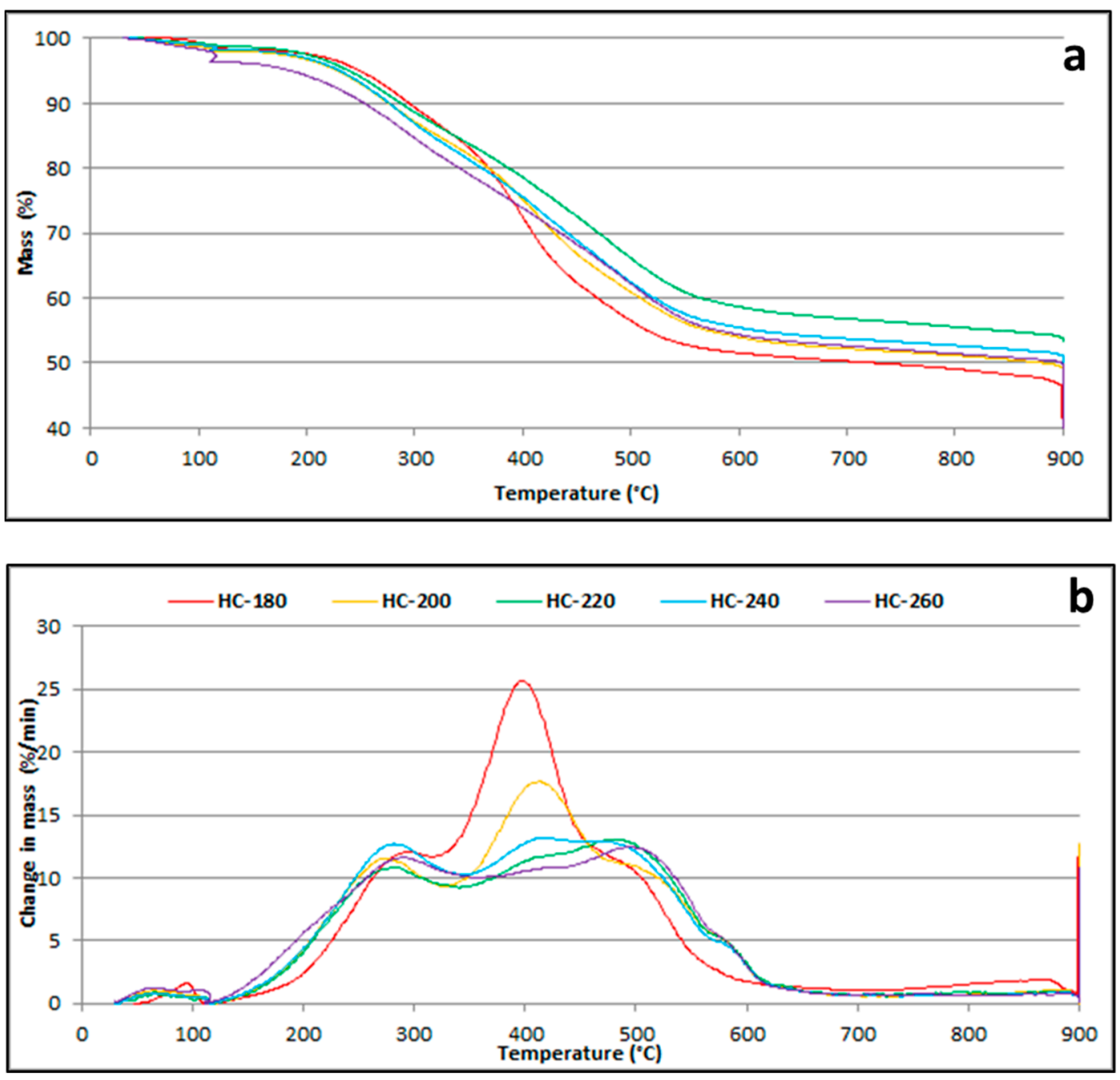

Figure 5. Thermogravimetric (TG) (a) and differential thermogravimetric (DTG) (b) profiles of hydrochars derived from swine manure.

\subsubsection{Thermal Analysis}

The TG curves show similar decomposition for each char, except for HC-180. The TG curve associated with $260^{\circ} \mathrm{C}$ (HC-260) ran nearly parallel to the other profiles, although it was lower during the beginning stages of weight loss due to more mass loss at the dehydration stage $\left(\sim 110^{\circ} \mathrm{C}\right)$ due to the presence of the highest moisture content. Conversely, HC-200 mass was consistently higher than the rest, which was likely due to it having the highest residual ash, meaning less of that char decomposed due to it having a higher proportion of ash, but was otherwise similar to the rest. HC-180, however, showed a different trend and maintained a higher percentage of its original mass than the others initially, before a rapid drop off leading to HC-180 having the least mass retained in the sample. The difference in HC-180 from the others is highlighted further in the DTG, Figure 5b, where it had the largest peak by far, indicating that much of the mass was lost at a higher rate over a smaller temperature range than the others.

Differences in thermal decomposition between the chars are much more pronounced with the DTG curves. The DTG curves revealed that HTC-180 had the most prominent peak and showed a much higher maximum weight loss than the rest of the samples. Notably, HC-200 had the next largest peak, and the other char samples have similar profiles without large peaks around $400{ }^{\circ} \mathrm{C}$, such as $\mathrm{HC}-180$ an HC-200. This can likely be explained by the ignition temperatures as shown in Table 5, which features char profile characteristic parameters typically reported for chars determined by graphical methods 
that were commonly employed $[47,48]$. The more rapid weight loss of the low-temperature hydrochars was likely a result of later ignition. The ignition index was calculated for each sample; a higher index suggests better ignition properties [48]. HC-180 had the highest index by far, nearly double that of the next highest, despite having the highest ignition temperature. The rest were similar to each other, with no discernable trend as char preparation temperature increased.

Table 5. Fuel properties of hydrochars prepared at various temperatures.

\begin{tabular}{cccccccc}
\hline Sample & $\begin{array}{c}\mathbf{T}_{\mathbf{i}} \\
\left({ }^{\circ} \mathbf{C}\right)\end{array}$ & $\begin{array}{c}\mathbf{t}_{\mathbf{i}} \\
(\mathbf{m i n})\end{array}$ & $\begin{array}{c}\mathbf{R}_{\mathbf{m}} \\
(\mathbf{\%} / \mathbf{m i n})\end{array}$ & $\begin{array}{c}\mathbf{T}_{\mathbf{m}} \\
\left({ }^{\circ} \mathbf{C}\right)\end{array}$ & $\begin{array}{c}\mathbf{t}_{\mathbf{m}} \\
(\mathbf{m i n})\end{array}$ & $\begin{array}{c}\mathbf{T}_{\mathbf{b}} \\
\left({ }^{\circ} \mathbf{C}\right)\end{array}$ & $\begin{array}{c}\mathbf{D}_{\mathbf{i}} \\
\left(\times \mathbf{1 0}^{-\mathbf{2}}\right)\end{array}$ \\
\hline HC-180 & 304 & 9.3 & 25.66 & 416 & 10.5 & 710 & 3.65 \\
HC-200 & 277 & 10.2 & 16.46 & 431 & 11.6 & 657 & 1.79 \\
HC-220 & 253 & 10 & 12.37 & 504 & 12.3 & 661 & 1.02 \\
HC-240 & 232 & 9.7 & 13.02 & 433 & 11.6 & 658 & 1.86 \\
HC-260 & 235 & 9.8 & 12 & 513 & 12.4 & 659 & 1.51 \\
\hline
\end{tabular}

Legend: $T_{i}$-ignition temperature, $t_{i}$-ignition temperature, $R_{m}$-max weight loss rate, $T_{m}$ 一temperature at $R_{m}$, $t_{m}$-time at $R_{m}, T_{b}$ - burnout temperature, Di-ignition index $=R_{m} /\left(t_{m} \times t_{i}\right)$.

\subsubsection{Oxidation kinetics}

Kinetic analyses were performed to estimate the activation energies and frequency factors [47,48]. Given that these profiles represent char pyrolysis, a first-order chemical reaction model was used to fit the data $\left(R^{2}=0.946\right.$ and 0.995). Kinetic parameters can be found in Table 6 that indicated that each char sample had two combustion stages with activation energies (E) in the range of 10.62 to $24.88 \mathrm{~kJ} / \mathrm{mol}$ and 26.16 to $32.58 \mathrm{~kJ} / \mathrm{mol}$, respectively. Our results are consistent with other hydrochars derived from palm empty fruit bunches and sewage sludge, respectively. The activation energies of palm empty fruit bunch chars were in the ranges of 15.85 to $30.24 \mathrm{~kJ} / \mathrm{mol}$ for the first stage and $12.91-20.70 \mathrm{~kJ} / \mathrm{mol}$ for the second stage [48]. For sewage sludge hydrochars, activation energies were in the ranges of 25.62 to $41.50 \mathrm{~kJ} / \mathrm{mol}$ for the first stage and 24.48 to $37.19 \mathrm{~kJ} / \mathrm{mol}$ for the second stage [47]. Similarly, the authors of [49] reported activation energies of $93-130 \mathrm{~kJ} / \mathrm{mol}$ and $52-63 \mathrm{~kJ} / \mathrm{mol}$ for the first and second stages, respectively, for hydrochars prepared from bamboo. Further, the authors of [32] tested the HTC of swine manure and reported activation energies of 120-124 kJ/mol. Overall, the activation energies of hydrochar were generally lower than that of bituminous fossil fuel coals, which are in the range of $85-160 \mathrm{~kJ} / \mathrm{mol}[50]$.

Table 6. Kinetic parameters of manure-derived hydrochars.

\begin{tabular}{ccccccccccc}
\hline Sample & \multicolumn{2}{c}{ HC-180 } & \multicolumn{2}{c}{ HC-200 } & \multicolumn{2}{c}{ HC-220 } & \multicolumn{2}{c}{ HC-240 } & \multicolumn{2}{c}{ HC-260 } \\
\hline $\begin{array}{c}\text { Temperature range }\left({ }^{\circ} \mathrm{C}\right) \\
\text { Activation Energy }\end{array}$ & $169-316$ & $316-615$ & $156-326$ & $326-647$ & $158-341$ & $341-650$ & $152-342$ & $342-647$ & $141-362$ & $362-647$ \\
$\quad(\mathrm{~kJ} / \mathrm{mol})$ & 24.04 & 32.58 & 18.78 & 26.58 & 24.88 & 27.54 & 20.36 & 26.23 & 10.62 & 26.16 \\
$\begin{array}{c}\text { Pre-exponential factor } \\
(1 / \mathrm{min})\end{array}$ & 116.9 & 893.9 & 41.5 & 233.2 & 189.7 & 261.8 & 66.4 & 221.1 & 5.7 & 218.3 \\
$\mathrm{R}^{2}$ & 0.965 & 0.995 & 0.973 & 0.98 & 0.992 & 0.965 & 0.977 & 0.972 & 0.951 & 0.946 \\
\hline
\end{tabular}

Despite favorable thermal properties, the ash contents were found to be between $35 \%$ and $38 \%$. Several authors also reported higher ash contents that increased when the process temperatures were increased. Lang et al. [3] observed an increase of ash from $21 \%\left(180^{\circ} \mathrm{C}\right)$ to $23 \%(23 \%)$. However, when increased amounts of $\mathrm{CaO}$ were added to the HTC process, the ash contents increased substantially, from $21 \%$ to $36 \%$. Similarly, the authors of [11] also observed that ash content increased from $17 \%$ to $21 \%$ when HTC temperatures were increased from 140 to $220^{\circ} \mathrm{C}$. These results suggest that hydrochars derived from swine manure may not be an ideal source for energy generation. In addition, the presence of heavy metals makes hydrochars less appealing as an energy source. Further, it may be noted that the HTC process usually concentrates phosphorus, potassium, and other elements in the resulting hydrochars. As suggested by [28,51], the presence of metal cations will result in an insoluble form 
of phosphorus that is immobilized within the hydrochar matrix. Song et al. [4] reported an increase in phosphorus from $5 \%$ to $6.5 \%$ when the processing temperatures were increased from $160{ }^{\circ} \mathrm{C}$ to $240{ }^{\circ} \mathrm{C}$. The increase in process time from $1 \mathrm{~h}$ to $8 \mathrm{~h}$ also resulted in similar increases in phosphorus concentrations in hydrochars. Similarly, Gasco et al. [30] observed that the HTC process at $240{ }^{\circ} \mathrm{C}$ increased the potassium concentration from $2.4 \mathrm{~g} / \mathrm{Kg}$ (manure) to $3.5 \mathrm{~g} / \mathrm{Kg}$ (hydrochar). Therefore, soil conditions are to be assessed recommending using hydrochars as soil amendments. Nonetheless, due to the presence of surface nitrogen groups, especially pyridinic (N6) and pyrrolic (N5) functionalities, swine manure-derived hydrochars can serve as excellent materials for mitigating organic pollutants and acidic species from water or air.

\section{Conclusions}

Swine manure slurry was converted into hydrochars via hydrothermal carbonization. Results indicated that swine manure-derived hydrochars had energy content comparable to coal. While increasing temperature led to an overall decrease in char yields, it did not appear to enhance the decomposition properties of hydrochar, suggesting that future processes would produce more favorable results by choosing a lower temperature range when utilizing this biomass. The thermogravimetric data suggested that the activation energies were comparable to the hydrochars synthesized from plant-based biomasses. However, due to the presence of significant proportions of ash, hydrochars derived from swine manure are not readily suitable as a combustible energy source. Nonetheless, the hydrochars were found to be equipped with nitrogen functional groups, namely, pyridinic and pyrrolic groups on the surface with an increase in temperatures led to an increase in pyridinic rings and decrease in pyrrolic rings, opening the possibilities of using hydrochars as precursors to selective adsorbents and energy storage devices. Further, the $\mathrm{pH}$ values and the points are zero charges suggested that the hydrochars are near neutral when processed at higher temperatures and may be applied as soil remediation agents.

Supplementary Materials: The following are available online at http://www.mdpi.com/2227-9717/7/9/560/s1, Figure S1a-i: Figure S1a Manure C 1s, Figure S1b Manure O 1s; Figure S1c Manure N 1s; Figure S1d HC-180 C 1s; Figure S1e HC-180 O 1s; Figure S1f HC-180 N 1s; Figure S1g HC-240 C 1s; Figure S1h HC-240 O 1s; Figure S1i HC-240 N 1s.

Author Contributions: Conceptualization, P.K. and J.J.C.; Methodology, Z.L.; Formal analysis, Z.L; Writing—original draft preparation, Z.L.; Review and Editing, P.K.

Funding: This research was funded by the North Carolina Agricultural Foundation (NCAF) and "The APC was funded by NCAF and NCSU College of Agricultural and Life Sciences Biological and Agricultural Engineering".

Conflicts of Interest: The authors declare no conflict of interest. The funders had no role in the design of the study; in the collection, analyses, or interpretation of data; in the writing of the manuscript, or in the decision to publish the results.

\section{References}

1. 2012 Census of Agriculture-UNITED STATES DATA USDA, National Agricultural Statistics Service. Available online: https://www.agcensus.usda.gov/Publications/2012/Full_Report/Volume_1,_Chapter_1_US/ st99_1_017_019.pdf (accessed on 22 June 2019).

2. Kellogg, R.; Moffitt, D.C.; Gollehon, N.R. Estimates of Recoverable and Non-recoverable Manure Nutrients Based on the Census of Agriculture. United States Department of Agriculture Natural Resources Conservation Service. Available online: https://www.nrcs.usda.gov/wps/portal/nrcs/detail/national/technical/nra/rca/?cid= nrcseprd1360819 (accessed on 4 August 2019).

3. Lang, Q.; Zhang, B.; Liu, Z.; Jiao, W.; Xia, Y.; Chen, Z.; Li, D.; Ma, J.; Gai, C. Properties of hydrochars derived from swine manure by $\mathrm{CaO}$ assisted hydrothermal carbonization. J. Environ. Manag. 2019, 233, 440-446. [CrossRef] [PubMed]

4. Song, C.; Shan, S.; Müller, K.; Wu, S.; Niazi, N.K.; Xu, S.; Shen, Y.; Rinklebe, J.; Liu, D.; Wang, H. Characterization of pig manure-derived hydrochars for their potential application as fertilizer. Environ. Sci. Pollut. Res. 2018, 25, 25772-25779. [CrossRef] [PubMed] 
5. Lang, Q.; Zhang, B.; Liu, Z.; Chen, Z.; Xia, Y.; Li, D.; Ma, J.; Gai, C. Co-hydrothermal carbonization of corn stalk and swine manure: Combustion behavior of hydrochar by thermogravimetric analysis. Bioresour. Technol. 2019, 271, 75-83. [CrossRef] [PubMed]

6. Szögi, A.A.; Vanotti, M.B.; Stansbery, A.E. Reduction of ammonia emissions from treated anaerobic swine lagoons. Trans. Am. Soc. Agric. Biol. Eng. 2006, 49, 217-225. [CrossRef]

7. Hunt, P.G.; Matheny, T.A.; Ro, K.S.; Vanotti, M.B.; Ducey, T.F. Denitrification in anaerobic lagoons used to treat swine wastewater. J. Environ. Qual. 2010, 39, 1821-1828. [CrossRef] [PubMed]

8. Hamilton, D.W.; Kourtchev, I.; Ndegwa, P.; Cumba, H.J.; Gioelli, F. Methane and carbon dioxide emissions from simulated anaerobic swine manure treatment lagoons under summer conditions. Trans. Am. Soc. Agric. Biol. Eng. 2006, 49, 157-165. [CrossRef]

9. Blunden, J.; Aneja, V.P. Characterizing ammonia and hydrogen sulfide emissions from a swine waste treatment lagoon in North Carolina. Atmos. Environ. 2008, 42, 3277-3290. [CrossRef]

10. Lu, W.; Addy, M.; Liu, J.; Nekich, C.; Zhang, R.; Peng, P.; Cheng, Y.; Cobb, K.; Liu, Y.; Wang, H.; et al. Integrated process for anaerobically digested swine manure treatment. Bioresour. Technol. 2019, 273, 506-514.

11. Song, C.; Zheng, H.; Shan, S.; Wu, S.; Wang, W.; Christie, P. Low-temperature hydrothermal carbonization of fresh pig manure: Effects of temperature on characteristics of hydrochars. J. Environ. Eng. 2019, 145, 04019029. [CrossRef]

12. Jin, H.; Yan, D.; Zhu, N.; Zhang, S.; Zheng, M. Immobilization of metal(loid)s in hydrochars produced from digested swine and dairy manures. Waste Manag. 2019, 88, 10-20. [CrossRef]

13. Hu, B.; Wang, K.; Wu, L.; Yu, S.; Antonietti, M.; Titirici, M. Engineering Carbon Materials from the Hydrothermal Carbonization Process of Biomass. Adv. Mater. 2010, 22, 813-828. [CrossRef] [PubMed]

14. Lucian, M.; Volpe, M.; Fiori, L. Hydrothermal carbonization kinetics of lignocellulosic agro-wastes: Experimental data and modeling. Energies 2019, 12, 516. [CrossRef]

15. Funke, A.; Ziegler, F. Hydrothermal carbonization of biomass: A summary and discussion of chemical mechanisms for process engineering. Biofuels Bioprod. Biorefining 2010, 4, 160-177. [CrossRef]

16. Lucian, M.; Luca Fiori, L. Hydrothermal carbonization of waste biomass: Process design, modeling, energy efficiency and cost analysis. Energies 2017, 10, 211. [CrossRef]

17. Wang, T.; Zhai, Y.; Zhu, Y.; LI, C.; Zeng, G. A review of the hydrothermal carbonization of biomass waste for hydrochar formation: Process conditions, fundamentals, and physicochemical properties. Renew. Sustain. Energy Rev. 2018, 90, 223-247. [CrossRef]

18. Román, S.; Libra, J.; Berge, N.; Sabio, E.; Ro, K.; Li, L.; Ledesma, B.; Álvarez, A.; Bae, S. Hydrothermal carbonization: Modeling, final properties design and applications: A review. Energies 2018, 11, 216. [CrossRef]

19. Hoekman, S.K.; Broch, A.; Robbins, C. Hydrothermal carbonization (HTC) of lignocellulosic biomass. Energy Fuels 2011, 25, 1802-1810. [CrossRef]

20. Heilmann, S.M.; Davis, H.T.; Jader, L.R.; Lefebvre, P.A.; Sadowsky, M.J.; Schendel, F.J.; von Keitz, M.G.; Valentas, K.J. Hydrothermal carbonization of microalgae. Biomass Bioenergy 2010, 34, 875-882. [CrossRef]

21. Bezdek, R.H.; Wendling, R.M. The return on investment of the clean coal technology program in the USA. Energy Policy 2013, 54, 104-112. [CrossRef]

22. Shen, W.; Fan, W. Nitrogen-containing porous carbons: Synthesis and application. J. Mater. Chem. A 2013, 1, 999-1013. [CrossRef]

23. Jain, A.; Xu, C.; Jayaraman, S.; Rajasekhar, B.; Lee, J.Y.; Srinivasan, M.P. Mesoporous activated carbons with enhanced porosity by optimal hydrothermal pre-treatment of biomass for supercapacitor applications. Microporous Mesoporous Mate. 2015, 218, 55-61. [CrossRef]

24. Kambo, H.S.; Dutta, A. A comparative review of biochar and hydrochar in terms of production, physico-chemical properties and applications. Renew. Sustain. Energy Rev. 2015, 45, 359-378. [CrossRef]

25. Fang, J.; Zhan, L.; Ok, Y.S.; Gao, B. Minireview of potential applications of hydrochar derived from hydrothermal carbonization of biomass. J. Ind. Eng. Chem. 2018, 57, 15-21. [CrossRef]

26. Ro, K.S.; Libra, J.A.; Bae, S.; Berge, N.D.; Flora, J.V.; Pecenka, R. Combustion behavior of animal-manure-based hydrochar and pyrochar. ACS Sustain. Chem. Eng. 2019, 7, 470-478. [CrossRef]

27. Cao, X.; Ro, K.S.; Chappell, M.; Li, Y.; Mao, J. Chemical Structures of Swine-Manure Chars Produced under Different Carbonization Conditions Investigated by Advanced Solid-State 13C Nuclear Magnetic Resonance (NMR) Spectroscopyt. Energy Fuels 2010, 25, 388-397. [CrossRef] 
28. Heilmann, S.M.; Molde, J.S.; Timler, J.G.; Wood, B.M.; Mikula, A.L.; Vozhdayev, G.V.; Colosky, E.C.; Spokas, K.A.; Valentas, K.J. Phosphorus reclamation through hydrothermal carbonization of animal manures. Environ. Sci. Technol. 2014, 48, 10323-10329. [CrossRef]

29. Ekpo, U.; Ross, A.B.; Camargo-Valero, M.A.; Fletcher, L.A. Influence of pH on hydrothermal treatment of swine manure: Impact on extraction of nitrogen and phosphorus in process water. Bioresour. Technol. 2016, 214, 637-644. [CrossRef]

30. Gasco, A.; Paz-Ferreiro, J.; Álvarez, M.L.; Saa, A.; Méndez, A. Biochars and hydrochars prepared by pyrolysis and hydrothermal carbonisation of pig manure. Waste Manag. 2018, 79, 395-403. [CrossRef]

31. Liu, Y.; Yao, S.; Wang, Y.; Lu, H.; Brar, S.K.; Yang, S. Bio-and hydrochars from rice straw and pig manure: Inter-comparison. Bioresour. Technol. 2017, 235, 332-337. [CrossRef]

32. Elder, J.P. Proximate analysis by automated thermogravimetry. Fuel 1983, 62, 580-584. [CrossRef]

33. Donahue, C.J.; Rais, E.A. Proximate analysis of coal. J. Chem. Educ. 2009, 86, 222. [CrossRef]

34. Cumming, J.W.; McLaughlin, J. The thermogravimetric behaviour of coal. Thermochim. Acta 1982, 57, $253-272$. [CrossRef]

35. Smith, M.; Scudiero, L.; Espinal, J.; McEwen, J.; Garcia-Perez, M. Improving the deconvolution and interpretation of XPS spectra from chars by ab initio calculations. Carbon 2016, 110 (Suppl. C), 155-171. [CrossRef]

36. Liu, Q.; Ke, M.; Liu, F.; Yu, P.; Hu, H.; Li, C. High-performance removal of methyl mercaptan by nitrogen-rich coconut shell activated carbon. RSC Adv. 2017, 7, 22892-22899. [CrossRef]

37. Lang, Q.; Guo, Y.; Zheng, Q.; Liu, Z.; Gai, C. Co-hydrothermal carbonization of lignocellulosic biomass and swine manure: Hydrochar properties and heavy metal transformation behavior. Bioresour. Technol. 2018, 266, 242-248. [CrossRef] [PubMed]

38. Hsu, J.-H.; Lo, S.H. Characterization and extractability of copper, manganese, and zinc in swine manure composts. J. Environ. Qual. 2000, 29, 447-453. [CrossRef]

39. Clanton, C.J.; Nichols, C.J.; Moser, R.L.; Ames, D.R. Swine manure characterization as affected by environmental temperature, dietary level intake, and dietary fat addition. Trans. Am. Soc. Agric. Eng. 1991, 34, 2164-2170. [CrossRef]

40. Medardus, J.J.; Molla, B.Z.; Nicol, M.; Morrow, W.M.; Rajala-Schultz, P.J.; Kazwala, R.; Gebreyes, W.A. In-feed use of heavy metal micronutrients in U.S. swine production systems and its role in persistence of multidrug-resistant Salmonellae. Appl. Environ. Microbiol. 2014, 80, 2317-2325. [CrossRef]

41. Wang, X.; Li, C.; Zhang, B.; Lin, J.; Chi, Q.; Wang, Y. Migration and risk assessment of heavy metals in sewage sludge during hydrothermal treatment combined with pyrolysis. Bioresour. Technol. 2016, 221, 560-567. [CrossRef]

42. Sun, J.; Zhang, Z.; Ji, J.; Dou, M.; Wang, F. Removal of Cr6+ from wastewater via adsorption with high-specific-surface-area nitrogen-doped hierarchical porous carbon derived from silkworm cocoon. Appl. Surf. Sci. 2017, 405, 372-379. [CrossRef]

43. Deng, Y.; Xie, Y.; Zou, K.; Ji, X. Review on recent advances in nitrogen-doped carbons: Preparations and applications in supercapacitors. J. Mater. Chem. A 2016, 4, 1144-1173. [CrossRef]

44. Nethaji, S.; Sivasamy, A.; Thennarasu, G.; Saravanan, S. Adsorption of Malachite Green dye onto activated carbon derived from Borassus aethiopum flower biomass. J. Hazard. Mater. 2010, 181, 271-280. [CrossRef] [PubMed]

45. Elaigwu, S.E.; Greenway, G.M. Characterization of energy-rich hydrochars from microwave-assisted hydrothermal carbonization of coconut shell. Waste Biomass Valorization 2019, 10, 1979-1987. [CrossRef]

46. U.S. Energy Information Administration. What is the Heat Content of U.S. Coal? U.S. Energy Information Administration: Washington, DC, USA, 2017. Available online: https://www.eia.gov/tools/faqs/faq.php?id= $72 \& \mathrm{t}=2$ (accessed on 30 November 2017).

47. Peng, C.; Zhai, Y.; Zhu, Y.; Xu, B.; Wang, T.; Li, C.; Zeng, G. Production of char from sewage sludge employing hydrothermal carbonization: Char properties, combustion behavior and thermal characteristics. Fuel 2016, 176 (Suppl. C), 110-118. [CrossRef]

48. Parshetti, G.K.; Kent Hoekman, S.; Balasubramanian, R. Chemical, structural and combustion characteristics of carbonaceous products obtained by hydrothermal carbonization of palm empty fruit bunches. Bioresour. Technol. 2013, 135 (Suppl. C), 683-689. [CrossRef] 
49. Yang, W.; Wang, H.; Zhang, M.; Zhu, J.; Zhou, J.; Wu, S. Fuel properties and combustion kinetics of hydrochar prepared by hydrothermal carbonization of bamboo. Bioresour. Technol. 2016, 205, 199-204. [CrossRef]

50. Gao, J.; Chang, M.; Shen, J. Comparison of bituminous coal apparent activation energy in different heating rates and oxygen concentrations based on thermo gravimetric analysis. J. Therm. Anal. Calorim. 2017, 130, 1181-1189. [CrossRef]

51. Huang, R.; Fang, C.; Lu, X.; Jiang, R.; Tang, Y. Transformation of phosphorus during (Hydro)thermal treatments of solid biowastes: Reaction mechanisms and implications for $\mathrm{P}$ reclamation and recycling. Environ. Sci. Technol. 2017, 51, 10284-10298. [CrossRef]

(C) 2019 by the authors. Licensee MDPI, Basel, Switzerland. This article is an open access article distributed under the terms and conditions of the Creative Commons Attribution (CC BY) license (http://creativecommons.org/licenses/by/4.0/). 